\title{
A physical model for the interaction between unsaturated soils and retaining structures
}

\author{
Gianluca Speranza $^{1, *}$, Alessio Ferrari ${ }^{1,2}$, and Lyesse Laloui ${ }^{1}$ \\ ${ }^{1}$ Swiss Federal Institute of Technology in Lausanne, EPFL, Laboratory of Soil Mechanics, LMS, Station 18, CH 1015, Lausanne, \\ Switzerland \\ ${ }^{2}$ Università degli Studi di Palermo, Engineering Department, Italy
}

\begin{abstract}
Temporary and permanent retaining structures interact with soils that are usually in unsaturated conditions. In this work, a $1 \mathrm{~g}$-scale physical model is presented to investigate the interactions between retaining walls and unsaturated soils. The physical model is equipped with a water-filled hydraulic cylinder connected to a pressure-volume controller to measure the horizontal component of the later earth thrust and high capacity tensiometers to measure soil matric suction. A system of low-friction linear guideways has been installed at the base of the wall-model. The failure surface is observed through a $3 \mathrm{~cm}$ thick glass wall on one side of the container. A series of images are acquired during the tests, and Particle Image Velocimetry (PIV) technique has been used to identify the displacement field. Selected test results on a fine sandy soil are presented, emphasizing the differences in the lateral thrust between dry and partially saturated conditions. The presented results show the impact of the partially saturated condition on both the magnitude of the horizontal component of the lateral earth thrust and the failure mechanism at active state.
\end{abstract}

\section{Introduction}

The lateral earth thrust acting on retaining structures depends on the soil-structure interaction, type of wall movement, soil, and wall's properties. Conventional geotechnical analyses consider the soils either totally dry or totally saturated. However, retained soils are often in partially saturated conditions during part or all of the retaining structure's life span. The interaction between dry or saturated soils with retaining structures has been deeply investigated. Yet, the effects of the partially saturated condition on the lateral earth thrust have to be well established. In the literature, the well-known Rankine, (1857) [1]'s theory and Coulomb (1776) [2]'s method have been systematically extended by considering the increase of shear strength provided by the presence of negative pore water pressure. Some examples can be found in Pufhal et al., (1983), Lu \& Likos, (2004) and Vahedifard et al., (2015) [3-5]. These studies provided helpful analytical methods for the computation of the lateral earth thrust. On the other hand, experimental evidence targeted to observe the soilstructure interaction in unsaturated conditions and validate the analytical formulations is still limited. An attempt can be found in Vo et al., (2016) [6], in which the authors studied the passive state of a rotating rigid retaining wall interacting with an unsaturated silty soil.

In this work, a new physical model capable of investigating the interaction between retaining walls and unsaturated soil is presented. The physical model is capable of reproducing several soil conditions; starting from the at-rest state, both the active and the passive state can be reached by controlling the horizontal displacement. The horizontal component of the lateral earth thrust can be controlled or measured. The position of the water level can be controlled below the wall model, and pore water pressure (positive or negative) can be measured continuously at different depths within the retained soil.

First, the experimental set-up and the monitoring instrumentations are described, then selected test results are presented, emphasizing the differences in the lateral thrust and the failure mechanism between dry and partially saturated conditions at active state. The tested material is a fine sand that has been characterized in terms of physical and hydro-mechanical properties.

\section{Material and methods}

\subsection{The experimental set-up}

The physical model (Fig.1) has been designed and manufactured at the Laboratory for Soil Mechanics of the Swiss Federal Institute of Technology in Lausanne. The dimensions of the whole container are $130 \mathrm{~cm}$ by $100 \mathrm{~cm}$ by $100 \mathrm{~cm}$. The supporting structure of both the container and the wall-model is made of reinforced steel to prevent lateral deformations, while two walls of the box are made of aluminum and one of glass.

The model can host $0.4 \mathrm{~m}^{3}$ of soil. The complementary portion of the volume is used for the

Corresponding author: gianluca.speranza@epfl.ch 
allocation of the wall-model and the measuring devices. bThe height of the wall-model is $50 \mathrm{~cm}$, while the retained soil can have a maximum depth of $80 \mathrm{~cm}$. The height of the wall-model was chosen to have a ratio of $1: 2$ respect to the width of the soil. In this way, according to Bransby \& Smith (1975) [7], the influence of the side effects is reduced. The space below the retaining wall is used to model the presence of a groundwater table. At the bottom of the container, a layer of gravel and a geotextile were placed, allowing a homogenous water distribution at the base of the retained soil. By connecting the container to an external reservoir, the groundwater level below the model of the retaining structure was controlled.

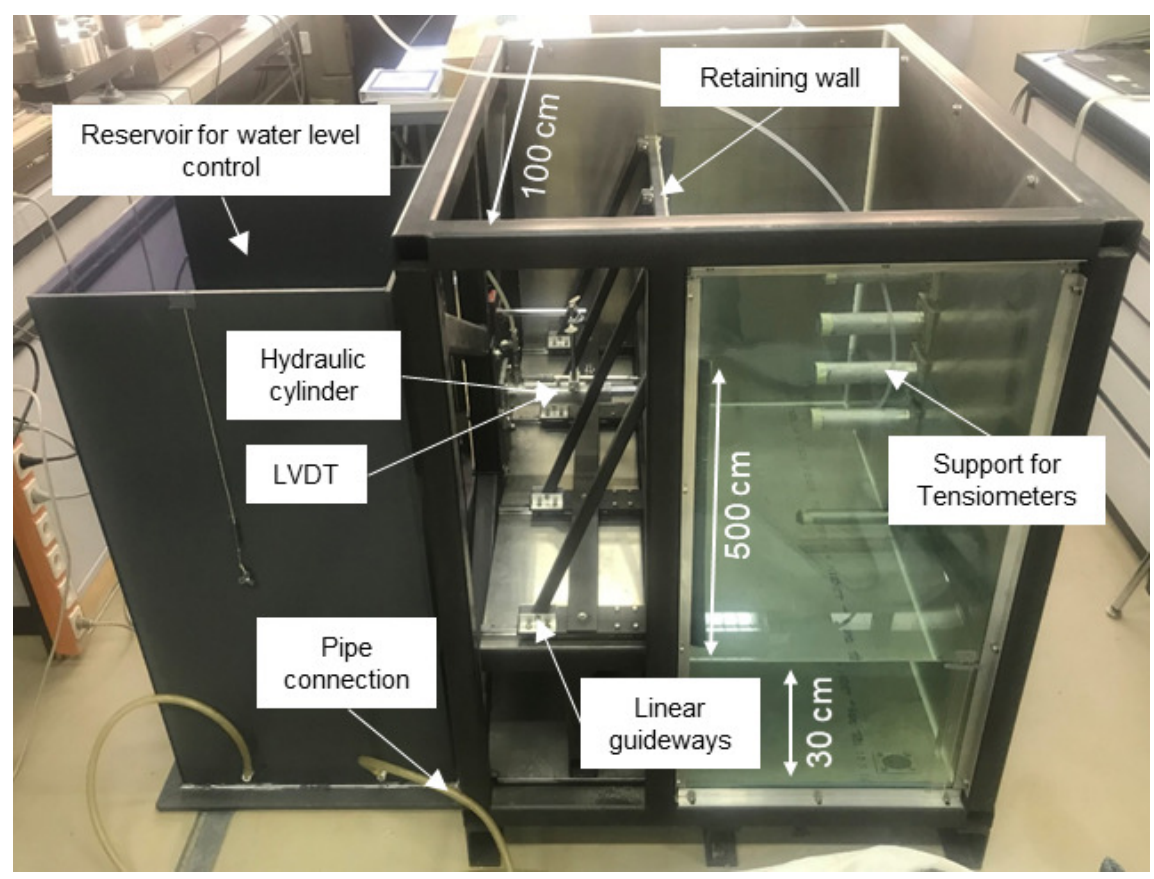

Fig.1. A general overview of the experimental set-up.

The physical model is equipped with a water-filled hydraulic cylinder (wHC) to measure the horizontal component of the lateral earth thrust and high capacity tensiometers (HCTs) to measure soil matric suction. A system of low friction linear guideways has been installed at the base of the wall-model. An LVDT is used to measure the horizontal displacement of the wall. The failure surface is observed through a $3 \mathrm{~cm}$ thick glass wall on one side of the container, and a series of images are acquired during the tests. Particle Image Velocimetry (PIV) technique has been used to identify the displacement field and to observe the failure surface. A NIKON D3300 camera was used to acquire pictures to perform the analysis. To ensure the acquisition of suitable pictures for the PIV, two LED lights were placed on the two sides of the camera.

The wHC was installed on the back of the wall, at $16.5 \mathrm{~cm}$ of height from its base. It was connected with a pressure-volume controller; by controlling either the pressure or the volume in the $\mathrm{wHC}$, it is possible to control the horizontal component of the force acting on the wall or its displacement. The wHC was calibrated in a frame equipped with a load cell to identify the relation between the applied force and the pressure in the controller.

Five cylindrical supports for tensiometer were installed horizontally close to the expected failure surface within the soil body. Their diameter is $3 \mathrm{~cm}$, and they are $25 \mathrm{~cm}$ long. The Trento High Capacity Tensiometers [8] are employed for the measurement of matric suction. Their operative range is $0-1500 \mathrm{kPa}$. The first saturation of the tensiometers was performed in the dedicated saturation chamber according to the procedure proposed by Tarantino \& Mongiovì, 2002 [8]: first, the vacuum was created in the reservoir of the instruments then water was injected through the ceramic disk. The tensiometers were calibrated in the range of $0-100 \mathrm{kPa}$.

\subsection{Tested soil}

The first set of tests have been conducted on the Itterbeck sand (SP, according to the Unified Soil Classification). The physical properties of the sand in terms of particle size distribution, minimum and maximum void ratio, and solid density are summarized in Table 1.

To characterize its mechanical properties, direct shear tests were performed. The peak $\left(\varphi_{P}^{\prime}\right)$ and the constant volume $\left(\varphi^{\prime} \mathrm{CV}\right)$ shear strength angle for the level of stress expected in the physical model resulted in being $56^{\circ}$ and $32^{\circ}$, respectively.

The water retention behaviour was characterized by employing the hanging water column method [9]. Both the drying and the wetting path were investigated. The results of the tests are reported in Fig. 2. The obtained 
experimental data were fitted to Van Ghenucten (1980)'s model [10]:

$$
S_{r}=\left(\frac{1}{1+\left[\alpha\left(u_{a}-u_{w}\right)\right]^{n}}\right)^{m}
$$

where $S_{r}$ is the degree of saturation, $u_{a}$ the air pressure, $\mathrm{u}_{\mathrm{w}}$ the water pressure, $\alpha, \mathrm{n}, \mathrm{m}$ fitting parameters. The obtained parameters are reported in Table 2 for both the main drying and the main wetting path.

\subsection{The experimental phases}

Two types of experiments are presented in this work: Test 1 in dry condition and Test 2 in unsaturated condition. Test 1 has been performed two times (Test 1a and Test 1b) to check the repeatability of the experiments. The filling procedure was the same for the perfomed tests; first, the sand was poured in the container by dry-pluviation technique keeping the falling height constant $(50 \mathrm{~cm})$. Retaining structure model's height was divided into 5 parts $(10 \mathrm{~cm}$ each), and the box was filled in steps. The dry density $\left(\rho_{\mathrm{d}}\right)$ at the end of the filling procedure was on average $1685 \mathrm{~kg} / \mathrm{m}^{3}$ for all the performed tests. At the beginning of the filling phase, the volume in the wHC was kept constant, and the increase of its pressure was recorded. With the increase of the filling height, to keep the at-rest condition, any tendency of the wall to displace was prevented by controlling the pressure in the wHC allowing the soil-structure system to remain at its initial configuration.

Regarding Test 1, once the box was filled up to the required height, a displacement was applied to achieve the failure mechanism at the active state. The displacement was applied by controlling the volume in the hydraulic cylinder (displacement rate equal to 0.01 $\mathrm{mm} / \mathrm{sec}$ ). Regarding Test 2, before applying the displacement, the container was hydraulically connected with the external reservoir, and the groundwater table was set at the base of the retaining structure. After reaching the steady-state (monitored by observing the capillary rise), two tensiometers were installed in the unsaturated part of the retained soil (at $30 \mathrm{~cm}$ and $40 \mathrm{~cm}$ of depth). Once the suction values recorded by the tensiometers equalized, the same displacement rate of the previous test was imposed to observe the failure of the partially saturated soil. Images were taken during the transition between the at-rest state and the failure (active state) to perform PIV and observe the differences between the two tested conditions. The OpenPIV code [11] was employed for the analysis of the images. After a sensitivity analysis on the mesh size, both the interrogation windows size and the spacing were imposed equal to $32 \times 32$ pixels.

Table 1. Physical properties of the tested soil.

\begin{tabular}{|c|c|c|c|c|c|}
\hline $\begin{array}{c}\mathbf{D}_{\mathbf{1 0}} \\
{[\mathbf{m m}]}\end{array}$ & $\begin{array}{c}\mathbf{D}_{\mathbf{3 0}} \\
{[\mathbf{m m}]}\end{array}$ & $\begin{array}{c}\mathbf{D}_{\mathbf{6 0}} \\
{[\mathbf{m m}]}\end{array}$ & $\begin{array}{c}\mathbf{e}_{\min } \\
{[-]}\end{array}$ & $\begin{array}{c}\mathbf{e}_{\mathbf{m a x}} \\
{[-]}\end{array}$ & $\begin{array}{c}\boldsymbol{\rho}_{\mathbf{s}} \\
{\left[\mathbf{g} / \mathbf{c m}^{3}\right]}\end{array}$ \\
\hline 0.128 & 0.155 & 0.207 & 0.55 & 0.88 & 2.65 \\
\hline
\end{tabular}

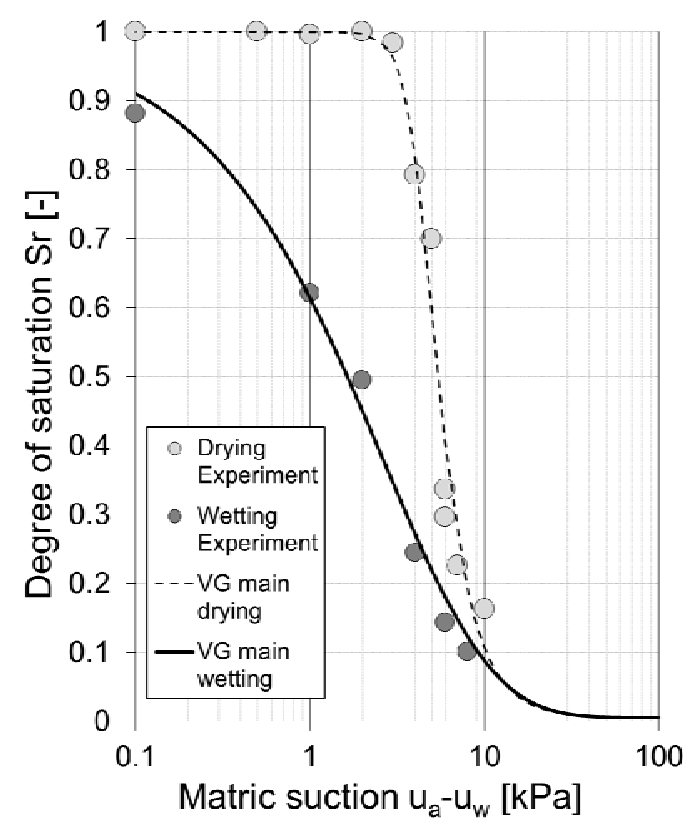

Fig. 2. Water retention behaviour: experimental data and adopted Van Genuchten's models.

Table 2. Van Genuchten models' parameters.

\begin{tabular}{|c|c|c|c|}
\hline Path [-] & $\boldsymbol{\alpha}[\mathbf{1 / k P a}]$ & $\mathbf{n}[-]$ & $\mathbf{m}[-]$ \\
\hline Drying & 0.23 & 6.23 & 0.44 \\
\hline Wetting & 0.004 & 0.75 & 27.77 \\
\hline
\end{tabular}

\section{Results of the tests}

The measurement of the force in the at-rest condition maintained during the backfilling allows a comparison with the lateral earth thrust coefficient from Jaky's formulation:

$$
K_{0}=1-\sin \varphi_{C V}^{\prime}
$$

The theoretical resultant of the horizontal component of the thrust $\left(\mathrm{F}_{0}\right)$ was computed as:

$$
F_{0}=\int_{0}^{H} K_{0} \sigma^{\prime}{ }_{v} d z=\int_{0}^{H} K_{0} \rho_{d} g z d z
$$

where $\rho_{\mathrm{d}}$ is the dry density, $\mathrm{g}$ the gravity acceleration and $\mathrm{z}$ the depth from the filled height $\mathrm{H}$.

Fig. 3 shows a comparison between the computed and the measured lateral earth thrust in Test $1 \mathrm{a}$ as a function of the filling height. Similar trends were also obtained in Tests $1 \mathrm{~b}$ and 2 .

The depicted results confirm that eq. 3 is a good representation for granular soils [12].

Fig. 4 shows the measured force-displacement relationship $(\mathrm{F}-\delta)$ for all the tests. The measured horizontal force reduces progressively. Interpreting the results provided by the PIV analysis, it was possible to observe the formation of the failure surface. For Tests 1a and $1 \mathrm{~b}$, the failure mechanism is completely developed 
for horizontal displacement of $0.15-0.20 \mathrm{~mm}$. Afterward, with the increase of the displacement, up to 1 $\mathrm{mm}$ the force remains almost constant.

The failure surface, observed from the top of the model, propagated up to $28 \mathrm{~cm}$ from the wall (measured at the middle of the retained soil at $50 \mathrm{~cm}$ from the two lateral container's sides). By assuming a linear failure surface, a slope of $61^{\circ}$ was observed. Consequently, according to Rankine's theory, the back-calculated shear strength angle resulted in $32^{\circ}$, which was in agreement with the results of the direct shear tests.

In Test 2, the imposition of the groundwater table at the base of wall resulted in a capillary rise. The length of the partially saturated portion of the soil was $22.5 \mathrm{~cm}$ on average. At this stage, two tensiometers were placed 10 $\mathrm{cm}$ and $20 \mathrm{~cm}$ above the imposed water level in the unsaturated portion of the soil. Fig. 5 shows the evolution of the pore-water pressure recorded by the tensiometers. The tensiometeres were initially immerged in free water, and the measured water pressures were correctly equal to zero. During the installation phase, a significant variation of the water pressure was observed (positive values). After a few minutes, the recorded values of suctions equalized and remained stable. The displacement rate was imposed at 83 minutes and the force was recorded. No change in pore-water pressure was observed.

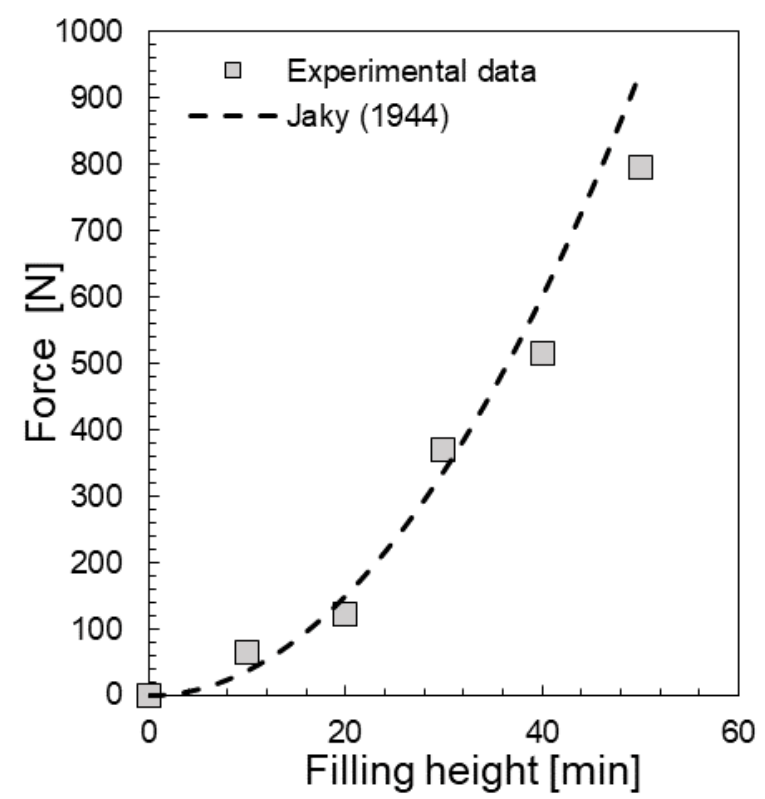

Fig. 3. Evolution of the horizontal component of the lateral earth thrust with the filling height in Test 1a. Comparison between Jaky's theory and experimental data.

At the end of the test, the tensiometers were removed and placed in free water. During this phase, first, the values of the recorded water pressure decreased as expected (variation of water pressure opposite to that observed during the tensiometers installation) then they came back to $0 \mathrm{kPa}$. This tensiometers' behaviour is considered satisfactory given that HCTs are usually employed for measuring higher suction values. The average suction values at $\mathrm{z}=30 \mathrm{~cm}$ and $\mathrm{z}=40 \mathrm{~cm}$ were respectively $3.2 \mathrm{kPa}$ and $2.5 \mathrm{kPa}$ with a standard deviation of $0.3 \mathrm{kPa}$ for both the tensiometers.

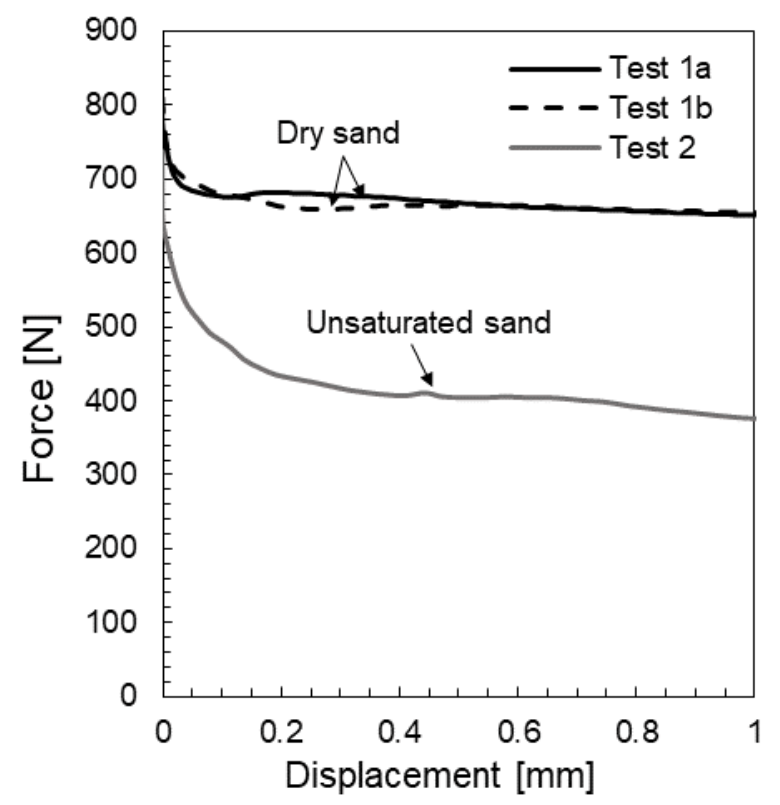

Fig. 4. Results of Test $1 \mathrm{a}, 1 \mathrm{~b}$, and 2 .

Regarding the F- $\delta$ relation, the active state seems to be obtained at higher displacements $(0.3-0.4 \mathrm{~mm})$ and with a lower value of the force compared to Test $1 \mathrm{a}$ and $1 b$.

The analyses of the PIV data allow for the identification of the failure surface that was different between the dry and the unsaturated case, as can be observed in Fig. 6. The frames were extrapolated every 30 seconds and were processed for the computation of the displacement field.

In the partially saturated condition, the failure surface is characterized by a double slope; in the unsaturated portion of the backfilling, the slope was higher respect to that observed in dry conditions, while in the upper part, almost the same slope of the dry case was observed. When the soil is unsaturated, the failure mechanism is influenced by the degree of saturation distribution or, in other words, by the negative pore-water pressures distribution.

\section{Conclusions}

In this work, a new physical model aimed to investigate the interaction between unsaturated soils and retaining structures has been presented. In the first part of the paper, the model has been detailed, describing its features and capabilities. Furthermore, the monitoring systems employed for the investigation of soil-structure interaction have been described. The hydro-mechanical properties of the tested material have been presented in terms of shear strength and water retention behaviour. The results of the tests in terms of failure surface and height of the capillary rise were found to be consistent with hydro-mechanical properties achieved in the laboratory. 
The results of the performed tests have shown that the physical model is capable of investigating the effects of partial saturation on the horizontal component of the lateral earth thrust.

The PIV has shown that the retained soils in unsaturated conditions (only capillary rise) can be characterized by a different failure surface respect to the case of dry soils. The slope of the failure surface is higher if the soil is unsaturated. Consequently, the failure mechanism was likely to be influenced by the partial saturation condition. The magnitude of the horizontal component of the lateral earth thrust was found to be lower respect to the dry condition.

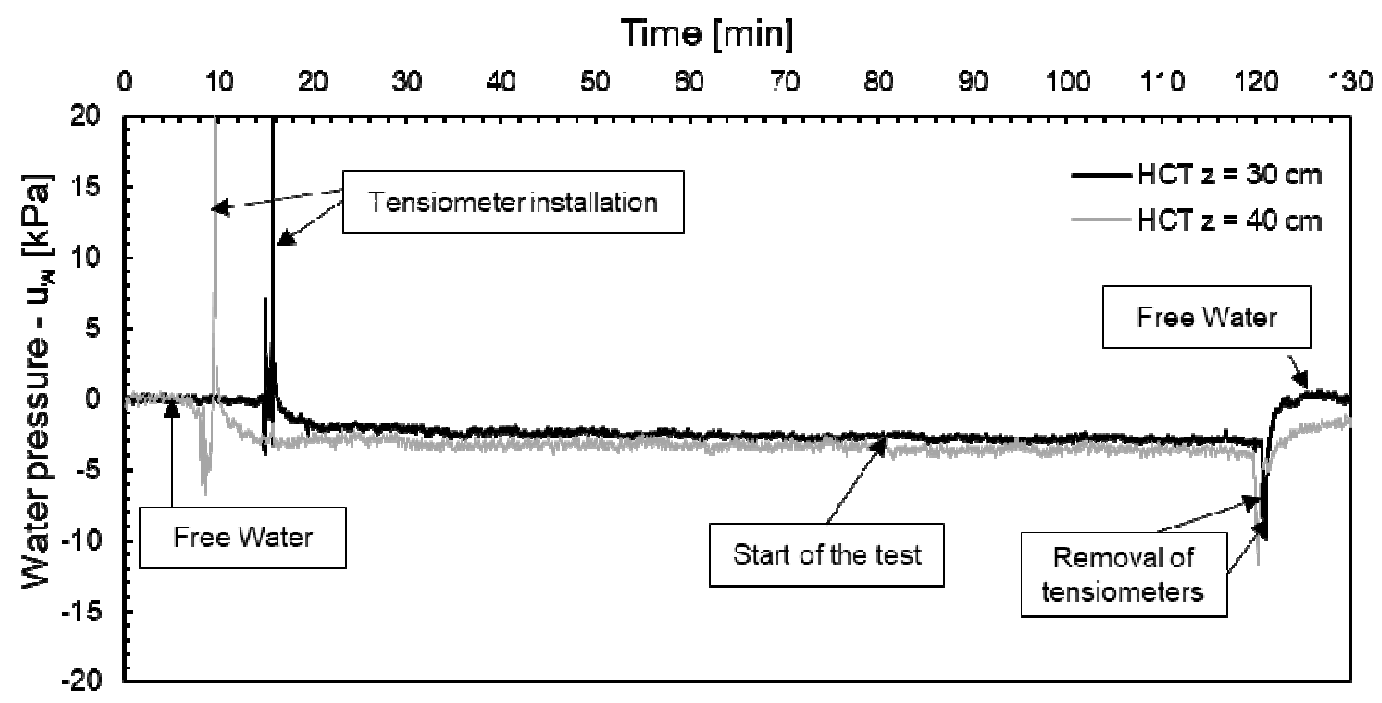

Fig. 5. Evolution of water pressure with time in test 2 .
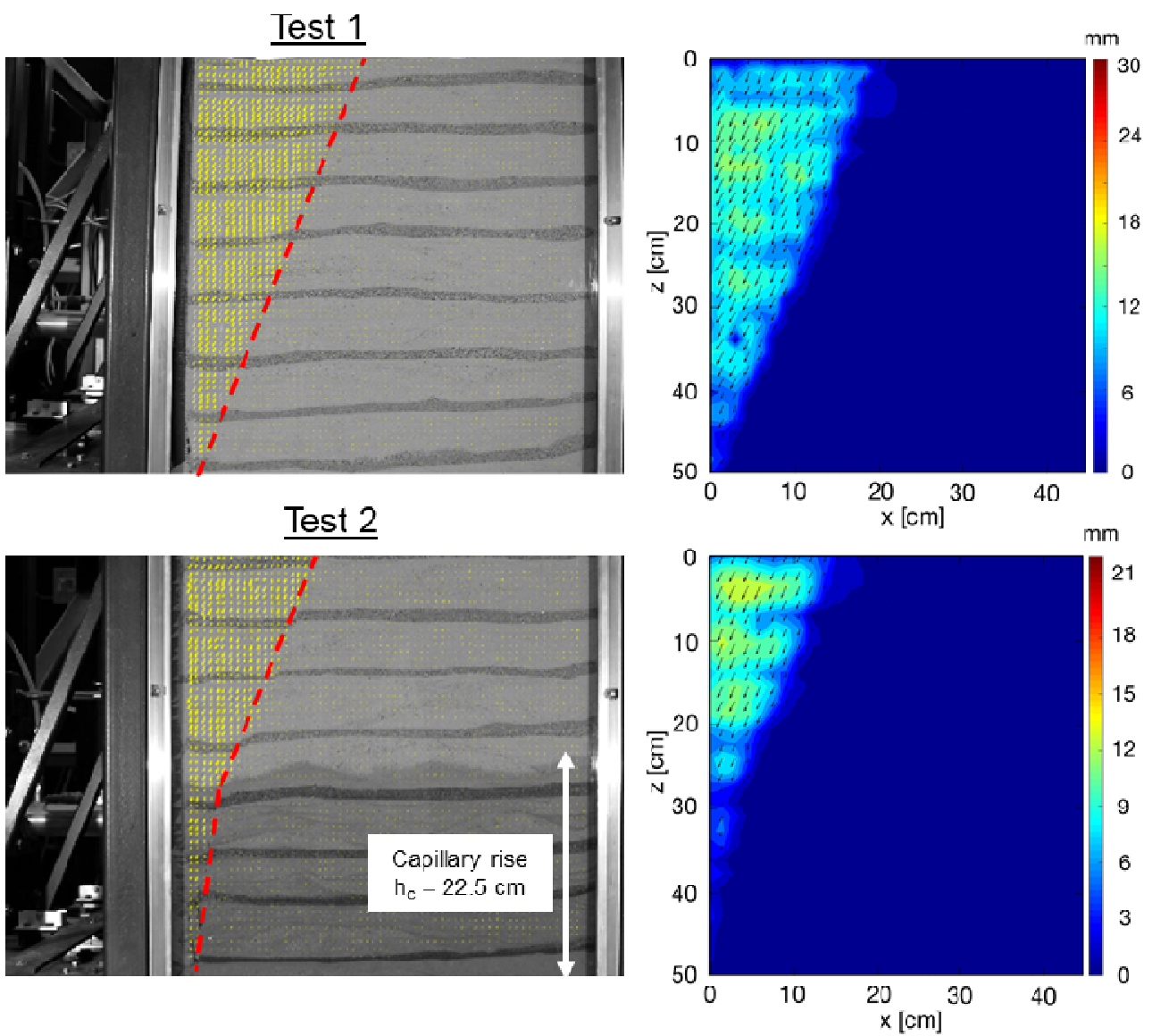

Fig. 6. Results of the PIV in terms of cumulated absolute displacements for the identification of the failure mechanisms. 


\section{Acknowledgments}

The authors wish to acknowledge the support of the European Commission via the Marie Skłodowska-Curie Innovative Training Networks (ITN-ETN) project TERRE 'Training Engineers and Researchers to Rethink geotechnical Engineering for a low carbon future' (H2020-MSCA-ITN2015-675762).

\section{References}

1. W.J.M. Rankine, II. On the stability of loose earth. Philosophical transactions of the Royal Society of London, 147, pp.9-27 (1857)

2. C.A. Coulomb. An attempt to apply the rules of maxima and minima to several problems of stability related to architecture. Mémoires de l'Académie Royale des Sciences, 7, pp.343-382, (1776)

3. D.E. Pufahl, D.G. Fredlund, and H. Rahardjo. Lateral earth pressures in expansive clay soils. Canadian Geotechnical Journal, 20(2), pp.228-241. (1983)

4. N. Lu, W. J. Likos, Unsaturated Soil Mechanics. Wiley, (2004)

5. F. Vahedifard, B. A. Leshchinsky, K. Mortezaei, N. $\mathrm{Lu}$, Active earth pressures for unsaturated retaining structures. Journal of Geotechnical and Geoenvironmental Engineering, 141.11, (2015)

6. T. Vo, H. Taiebat, A.R. Russell, Interaction of a rotating rigid retaining wall with an unsaturated soil in experiments. Géotechnique, 66(5), pp.366-377 (2016)

7. P.L. Bransby, and I.A. Smith, Side friction in model retaining-wall experiments. Journal of Geotechnical and Geoenvironmental Engineering, 101(7) pp.615-632 (1975).

8. A. Tarantino, L. Mongiovì, Design and construction of a tensiometer for direct measurement of matric suction. Proceedings 3rd International Conference on Unsaturated Soils, pp 319-324, (2002)

9. W.B. Haines, Studies in the physical properties of soil. V. The hysteresis effect in capillary properties, and the modes of moisture distribution associated therewith. The Journal of Agricultural Science, 20(1), pp.97-116 (1930).

10. M. Van Genuchten, A closed-form equation for predicting the hydraulic conductivity of unsaturated soils. Soil science society of America journal, 44(5), pp. 892-898 (1980)

11. Z.J. Taylor, R. Gurka, G.A. Kopp, and A. Liberzon, 2010. Long-duration time-resolved PIV to study unsteady aerodynamics. IEEE Transactions on Instrumentation and Measurement, 59(12), pp.3262-3269.

12. R.L. Michalowski, Coefficient of earth pressure at rest. Journal of geotechnical and geoenvironmental engineering, 131(11), pp.1429-1433 (2005). 